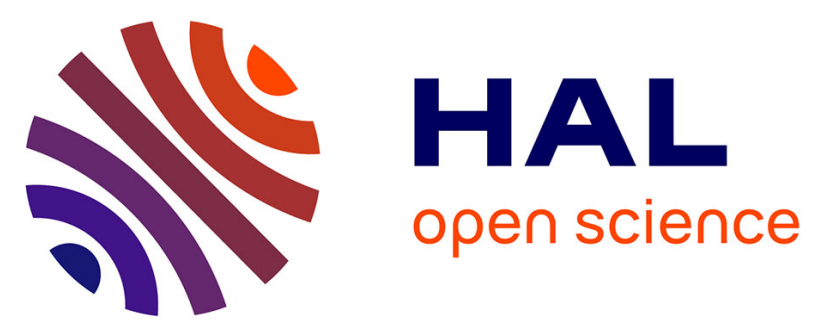

\title{
Chemical nature and thermal decomposition behavior of tartaric acid multilayers on rutile $\mathrm{TiO} 2$ (110)
}

\author{
Elisa Meriggio, Rémi Lazzari, Christophe Méthivier, Pascal David, Stéphane
}

Chenot, Xavier Carrier, Gregory Cabailh, Vincent Humblot

\section{To cite this version:}

Elisa Meriggio, Rémi Lazzari, Christophe Méthivier, Pascal David, Stéphane Chenot, et al.. Chemical nature and thermal decomposition behavior of tartaric acid multilayers on rutile $\mathrm{TiO} 2$ (110). Journal of Vacuum Science \& Technology B Microelectronics and Nanometer Structures, 2019, 37 (5), pp.051803. 10.1116/1.5100957 . hal-02340226

\section{HAL Id: hal-02340226 \\ https://hal.sorbonne-universite.fr/hal-02340226}

Submitted on 30 Oct 2019

HAL is a multi-disciplinary open access archive for the deposit and dissemination of scientific research documents, whether they are published or not. The documents may come from teaching and research institutions in France or abroad, or from public or private research centers.
L'archive ouverte pluridisciplinaire $\mathbf{H A L}$, est destinée au dépôt et à la diffusion de documents scientifiques de niveau recherche, publiés ou non, émanant des établissements d'enseignement et de recherche français ou étrangers, des laboratoires publics ou privés. 
Chemical nature and thermal decomposition behavior of tartaric acid multilayers on rutile $\mathrm{TiO}_{2}(110)$

Elisa Meriggio, Rémi Lazzari, Christophe Méthivier, Pascal David, Stéphane Chenot, Xavier Carrier, Gregory Cabailh, and Vincent Humblot

Citation: Journal of Vacuum Science \& Technology B 37, 051803 (2019); doi: 10.1116/1.5100957

View online: https://doi.org/10.1116/1.5100957

View Table of Contents: https://avs.scitation.org/toc/jvb/37/5

Published by the American Vacuum Society

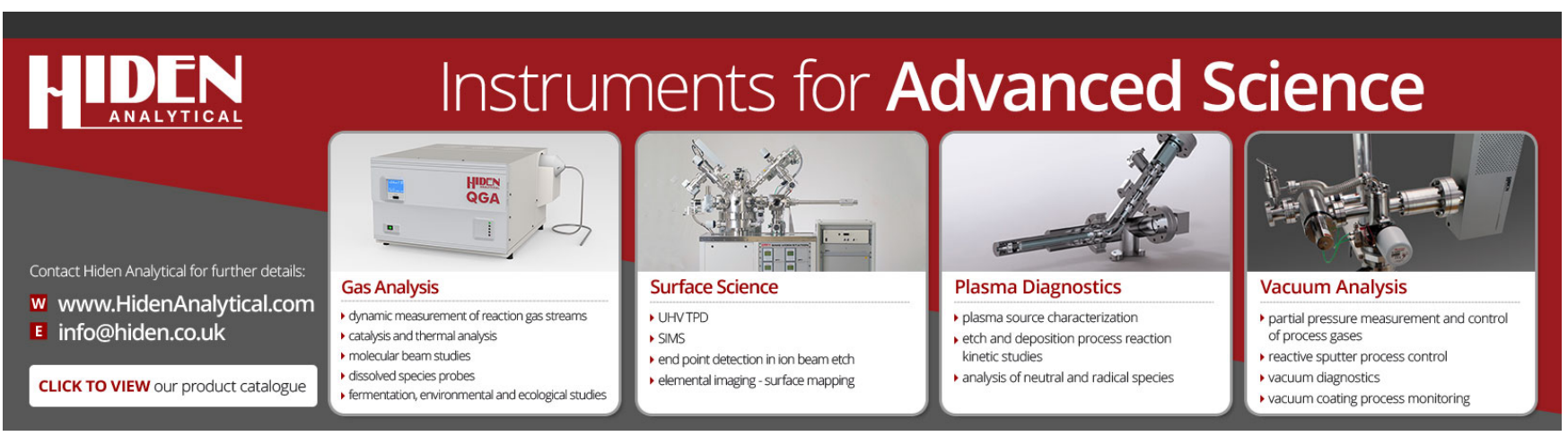




\title{
Chemical nature and thermal decomposition behavior of tartaric acid multilayers on rutile $\mathrm{TiO}_{2}(110)$
}

\author{
Elisa Meriggio, ${ }^{1,2}$ Rémi Lazzari, ${ }^{2}$ Christophe Méthivier, ${ }^{1}$ Pascal David, ${ }^{2}$ Stéphane Chenot, ${ }^{2}$ \\ Xavier Carrier, ${ }^{1}$ Gregory Cabailh, ${ }^{2, a)}$ and Vincent Humblot ${ }^{1, b)}$ \\ ${ }^{1}$ Laboratoire de Réactivité de Surface, Sorbonne Université, UMR CNRS 7197, 4 place Jussieu, 75252 Paris \\ Cedex 05, France \\ ${ }^{2}$ Institut des NanoSciences de Paris, Sorbonne Université, UMR CNRS 7588, 4 place Jussieu, 75252 Paris \\ Cedex 05, France
}

(Received 22 April 2019; accepted 9 July 2019; published 12 August 2019)

\begin{abstract}
$\mathrm{R}, \mathrm{R}$-tartaric acid (RR-TA) thermal stability and decomposition on the rutile $\mathrm{TiO}_{2}(110)$ surface was investigated by temperature programmed desorption. The authors show that a majority of RR-TA molecules are desorbed intact from multilayers at around $340 \mathrm{~K}$, while they decompose from the first chemisorbed layer between 460 and $480 \mathrm{~K}$. Complementary information on the chemical nature of RR-TA in the multilayer regime was gained by x-ray photoelectron spectroscopy, which shows that biacid molecules form the multilayer while they are monotartrate at the interface. Published by the AVS. https://doi.org/10.1116/1.5100957
\end{abstract}

\section{INTRODUCTION}

Chiral molecules, which are nonsuperimposable to their mirror image, are of prime importance for living organisms, since many biomolecules appear in only one handedness. ${ }^{1}$ Biological activities of opposite enantiomers may, thus, lead to drastic effects, which explain why gaining control of enantioselectivity is a major challenge in many fields, including pharmaceutical and agrochemical industries. ${ }^{2}$ Among several developed strategies for the production of enantiomerically pure compounds, asymmetric catalysis has been receiving increasing attention. ${ }^{3,4}$ Chiral molecules deposited in ultrahigh vacuum (UHV) conditions either on plane metal surfaces or on oxide-supported metal catalysts are used in surface science as model systems to investigate at a microscopic level the catalyst structure and understand the key steps of the catalytic processes. ${ }^{2,3,5-7}$ While metal surfaces have been intensively explored, fundamental questions remain on the role of the oxide supports in oxide-supported metal catalysts.

In this context, we focus here on $(\mathrm{R}, \mathrm{R})$-tartaric acid [HOOC-CH $(\mathrm{OH})-\mathrm{CH}(\mathrm{OH})-\mathrm{COOH}$, hereafter named RR-TA] and rutile $\mathrm{TiO}_{2}(110)$ single crystal as a model system of the interaction between a chiral molecule and an oxide substrate. The adsorption of RR-TA, one of the most efficient chiral modifier, has been investigated so far on several metal surfaces. ${ }^{5,8-19}$ Biacidic, monotartrate, or bitartrate molecules have been found upon adsorption, depending on how many $\mathrm{COOH}$ groups undergo deprotonation. ${ }^{5}$ The RR-TA thermal decomposition mechanism has been studied on $\mathrm{Cu},{ }^{10,17-19}$ $\mathrm{Ni}^{11-15}$ and Pd (Ref. 16) surfaces and has been found to strongly depend on the surface structure. On some surfaces, such as $\mathrm{Cu}(110)^{19-22}$ and $\mathrm{Ni}(110),{ }^{13}$ temperature programmed desorption (TPD) experiments have evidenced an explosive

Note: This paper is part of the Conference Collection from the AVS Pacific Rim Symposium on Surfaces, Coatings and Interfaces (PacSurf 2018) meeting.

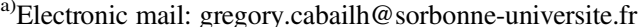

b)Electronic mail: vincent.humblot@sorbonne-universite.fr decomposition behavior for RR-TA by tracing the molecular decomposition products $\mathrm{H}_{2}, \mathrm{H}_{2} \mathrm{O}, \mathrm{CO}$, and $\mathrm{CO}_{2}$. However, the same desorption mechanism was not observed on other metal surfaces such as $\operatorname{Pd}(111)^{16}$ and $\mathrm{Ni}(111) .{ }^{11}$ Different surface structures, surface roughness, contaminations, and experimental conditions (mainly the adsorption temperature) have been proposed as possible explanations for the different observed behaviors. ${ }^{17}$

The interaction of carboxylic acid molecules with the rutile $\mathrm{TiO}_{2}$ (110) surface has received considerable attention. Upon adsorption, they present a common predisposition to deprotonate one or multiple $\mathrm{COOH}$ groups, with the carboxylate $\mathrm{O}$ atoms bound to two five-fold coordinated surface titanium $\mathrm{Ti}_{5 \mathrm{c}}$ atoms. ${ }^{23}$ In a previous work, we investigated RR-TA submonolayer and monolayer deposition on the rutile $\mathrm{TiO}_{2}(110)$ surface by combining several surface science techniques. ${ }^{24} \mathrm{We}$ have shown that RR-TA molecules adsorb on the oxide surface in a monotartrate form, i.e., only one of the two $\mathrm{COOH}$ groups deprotonates upon adsorption. The carboxylate oxygen atoms are bound to two adjacent $\mathrm{Ti}_{5 \mathrm{c}}$ atoms in the [001] direction and the remaining $\mathrm{COOH}$ group protrudes out of the surface. Moreover, at saturation of the first layer, low-energy electron diffraction (LEED) and STM evidenced the formation of an ordered $(2 \times 1)$ overlayer. Here, we extend the study to the RR-TA thermal stability and decomposition on $\mathrm{TiO}_{2}(110)$ as well as its adsorption behavior in the multilayer regime. It has already been observed experimentally that protruding carboxylic groups favor the formation of physisorbed multilayers. ${ }^{25}$ Hence, the interface layer formed by monotartrate species on $\mathrm{TiO}_{2}(110)$ with a free carboxylic group available at the surface should lead to a multilayer formation via $\mathrm{H}$-bond interactions.

\section{EXPERIMENT}

All experiments have been carried out in an UHV chamber at the Institut des Nanosciences de Paris laboratory, with a base pressure of $10^{-10} \mathrm{mbar}$ or better. The rutile $\mathrm{TiO}_{2}(110)$ surface has been intensively investigated in surface science thanks to 
the possibility of increasing the crystal conductivity by reducing the samples under UHV conditions, thus allowing its characterization by electron spectroscopies and scanning tunneling microscopy. ${ }^{23,26}$ The $\mathrm{TiO}_{2}(110)$ single crystal (Mateck GmbH, Germany) was cleaned by several cycles of $\mathrm{Ar}^{+}$sputtering at 1 $\mathrm{keV}$ and subsequent annealing at $1000 \mathrm{~K}$. XPS and LEED were used to verify the absence of contamination and the surface crystallinity, respectively. After the last annealing, the $\mathrm{TiO}_{2}$ sample was cooled down to room temperature, before RR-TA deposition.

Crystalline powder of $(\mathrm{R}, \mathrm{R})$-tartaric acid was provided by Acros Organics (Fisher Scientific SAS France) and deposited from a glass crucible resistively heated by a metallic wire wrapped around it, after having been degassed for several hours (for details see Ref. 24). The typical cell temperature is between 370 and $395 \mathrm{~K} \cdot{ }^{8,16}$ During RR-TA evaporation, the pressure in the UHV chamber rose reproducibly between 2 and $3 \times 10^{-9} \mathrm{mbar}$. Since the crucible is not equipped with a thermocouple, an accurate calibration is first performed by XPS. RR-TA coverage was estimated from the Ti2p/C1s XPS intensity ratio, assuming a homogeneous molecular film as detailed in Ref. 24. Knowing that in the submonolayer regime RR-TA binds to the $\mathrm{TiO}_{2}(110)$ surface in a monotartrate form (one RR-TA molecule every two surface $\mathrm{Ti}_{5 \mathrm{c}}$ atoms), the monolayer saturation coverage is defined as half of $\mathrm{Ti}_{5 \mathrm{c}}$ density of the exposed surface $\left(5.2 \times 10^{14} \mathrm{~cm}^{-2}\right),{ }^{27}$ which corresponds to an equivalent film thickness of about 6-7 $\AA$.

XPS was performed using a nonmonochromatic dual anode $\mathrm{Al} / \mathrm{Mg} \mathrm{K} \alpha$ x-ray source $(\mathrm{h} v=1486.6 \mathrm{eV})$ and a hemispherical analyzer (Omicron EA 125). Multilayer TA molecules may desorb in UHV conditions during XPS analysis as observed in our previous study ${ }^{24}$ leading to a monolayer regime. In the present case, rapid XPS scans (less than a minute) were recorded in order to avoid multilayer TA desorption and to analyze the chemical state of RR-TA molecules in the multilayer regime. Spectra were taken at normal emission using a pass energy of $50 \mathrm{eV}$. The spectra were normalized to the background level on the low binding energy $\left(\mathrm{E}_{\mathrm{b}}\right)$ side of the peak. The XPS analysis was carried out with CASAXPS software, applying for the fit a Gaussian/Lorentzian ratio equal to 70/30.

TPD was carried out using a quadrupole mass spectrometer (QMG 220 from PFEIFFER) placed in a quartz tube differentially pumped by an ionic pump (for details see Ref. 28). The tube ends with a small cap pointing to the sample, the aperture of which is smaller than the sample surface. During TPD experiments, the tube is placed at about $1 \mathrm{~mm}$ from the $\mathrm{TiO}_{2}$ surface to drastically limit the detection of species desorbing from the surroundings. A linear heating rate $\alpha=0.5 \mathrm{~K} \mathrm{~s}^{-1}$ was applied to the sample up to a temperature of $800 \mathrm{~K}$, which was measured by a calibrated thermocouple spot-welded on the manipulator.

\section{RESULTS AND DISCUSSION}

\section{A. Thermal stability of RR-TA on rutile $\mathrm{TiO}_{2}(\mathbf{1 1 0})$}

TPD experiments were carried out to gain information on RR-TA thermal stability and decomposition behavior on
$\mathrm{TiO}_{2}(110)$. Based on the mass spectrum of RR-TA from the NIST database, ${ }^{29}$ the main ion fragments observed correspond to the mass to charge ratios $(\mathrm{m} / \mathrm{e})$ of 58 and 76 with relative intensities of 40 and 100, respectively. Hence, these fragments of the molecule have been tracked in the present TPD experiments. Moreover, $\mathrm{m} / \mathrm{e}=2\left(\mathrm{H}_{2}^{+}\right), 18\left(\mathrm{H}_{2} \mathrm{O}^{+}\right)$, $28\left(\mathrm{CO}^{+}\right)$, and $44\left(\mathrm{CO}_{2}^{+}\right)$were also monitored.

TPD spectra were recorded for the clean $\mathrm{TiO}_{2}(110)$ surface as a blank and following increasing doses of RR-TA at room temperature. The results obtained are summarized in Fig. 1 for $\mathrm{m} / \mathrm{e}=58\left(\mathrm{HOC}-\mathrm{COH}^{+}\right)$and $76\left(\mathrm{C}_{2} \mathrm{O}_{3} \mathrm{H}_{4}^{+}\right)$corresponding to the main two fragments ascribed to the molecular form and in Fig. 2 for $\mathrm{m} / \mathrm{e}=2\left(\mathrm{H}_{2}^{+}\right), 18\left(\mathrm{H}_{2} \mathrm{O}^{+}\right)$, $28\left(\mathrm{CO}^{+}\right)$, and $44\left(\mathrm{CO}_{2}^{+}\right)$. A particular attention has to be paid when considering $\mathrm{H}_{2}^{+}, \mathrm{H}_{2} \mathrm{O}^{+}, \mathrm{CO}^{+}$, and $\mathrm{CO}_{2}^{+}$fragments since they usually are the dominant residual gases in UHV chambers and their presence is inevitable when heating in UHV. To be sure that $\mathrm{H}_{2}^{+}, \mathrm{H}_{2} \mathrm{O}^{+}, \mathrm{CO}^{+}$, and $\mathrm{CO}_{2}^{+}$contributions truly arise from RR-TA molecular desorption, TPD
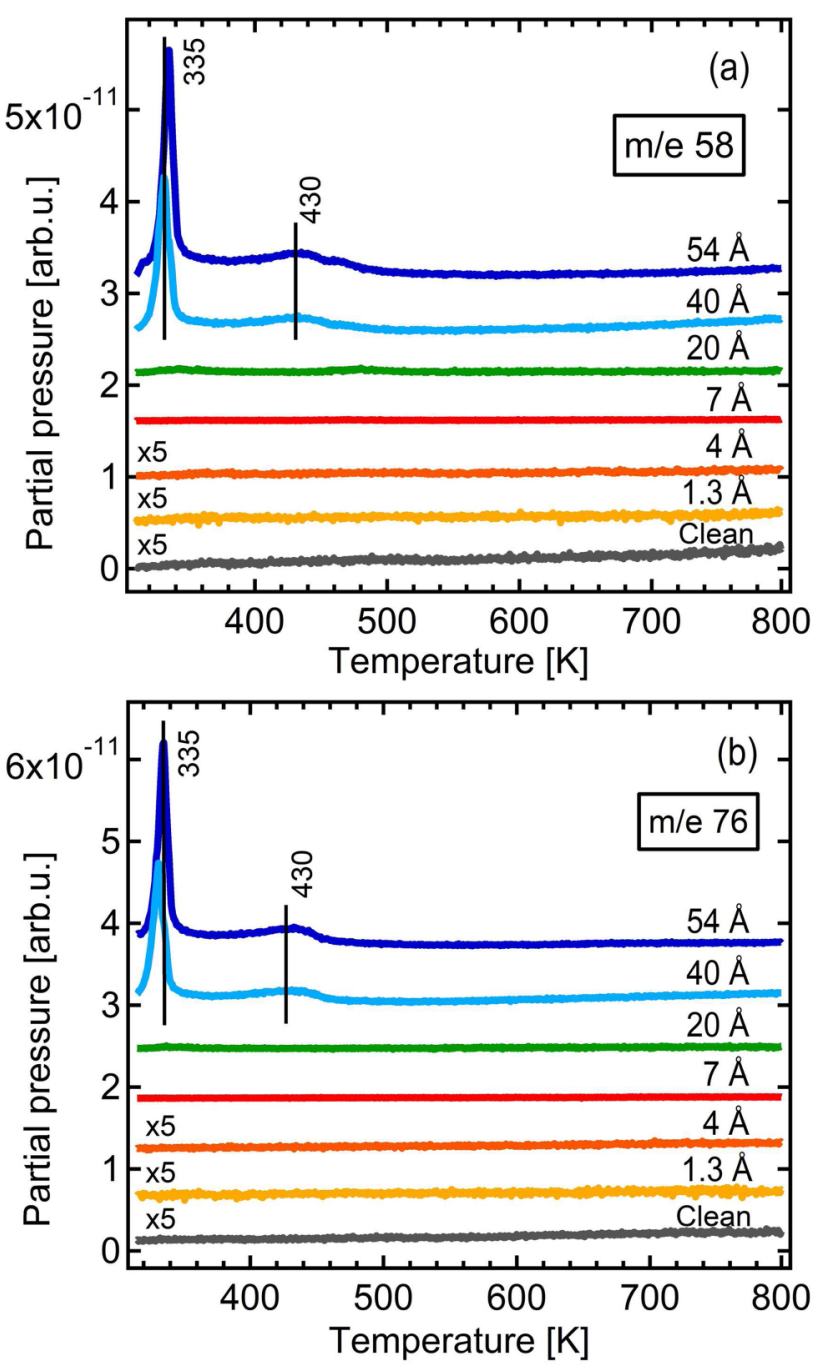

FIG. 1. TPD spectra of relative mass/charge (a) 58 and (b) 76 for increasing doses of RR-TA on $\mathrm{TiO}_{2}(110)$ at room temperature. The recorded spectra are vertically shifted for the sake of clarity. Scale factors are specified near the corresponding spectra. 

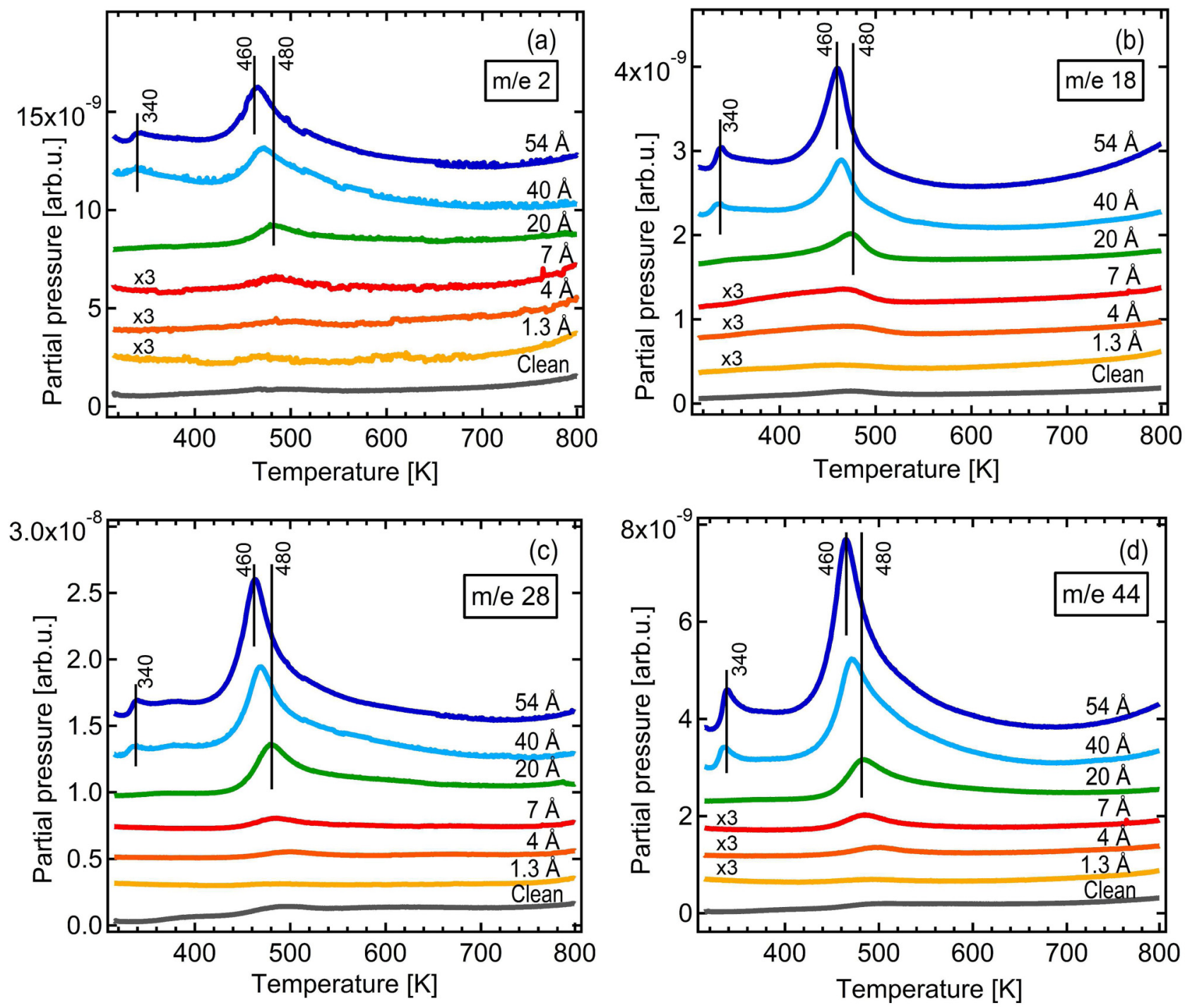

FIG. 2. TPD spectra of relative mass/charge (a) $2\left(\mathrm{H}_{2}^{+}\right)$, (b) $18\left(\mathrm{H}_{2} \mathrm{O}^{+}\right)$, (c) $28\left(\mathrm{CO}^{+}\right)$, and (d) $44\left(\mathrm{CO}_{2}^{+}\right)$for increasing doses of $\mathrm{RR}-\mathrm{TA}$ on $\mathrm{TiO} \mathrm{O}_{2}(110)$ at room temperature. The recorded spectra are vertically shifted for the sake of clarity. Scale factors are specified near the corresponding spectra.

spectra at increasing RR-TA coverage are compared to those recorded on the clean $\mathrm{TiO}_{2}$ surface.

After RR-TA doses, two main features are identified at about $335-340 \mathrm{~K}$ and $430-480 \mathrm{~K}$. The low temperature peak at $335-340 \mathrm{~K}$ appears very intense at high RR-TA doses for $\mathrm{m} / \mathrm{e}=58$ and 76 (Fig. 1), which are specific to RR-TA molecules, and does not saturate as the molecular dose increases. In analogy to previous findings for RR-TA on $\mathrm{Cu}(531)^{17}$ and on $\mathrm{Pd}(111),{ }^{16}$ the peak at $335-340 \mathrm{~K}$ is, thus, attributed to multilayer desorption. Desorption of the second molecular layer was found to occur around $330 \mathrm{~K}$ on $\mathrm{Pd}(111)$, in reasonable agreement with the present work. This peak is also far weaker for the molecular decomposition fragments $\mathrm{H}_{2}^{+}, \mathrm{H}_{2} \mathrm{O}^{+}$, $\mathrm{CO}^{+}$, and $\mathrm{CO}_{2}^{+}$, again suggesting molecular desorption.

For higher temperatures, the desorption feature between 430 and $480 \mathrm{~K}$ is consequently expected to arise from monolayer desorption. This contribution appears much more intense in the $\mathrm{H}_{2}^{+}, \mathrm{H}_{2} \mathrm{O}^{+}, \mathrm{CO}^{+}$, and $\mathrm{CO}_{2}^{+}$spectra and far less for the $\mathrm{m} / \mathrm{e}$ specific to the desorption of the intact RR-TA molecule. The intensity of this feature does not completely saturate and continues to slightly increase even for the higher doses; this fact may be explained by the formation of multilayers before the complete saturation of the first chemisorbed layer, as previously observed in the case of RR-TA on $\mathrm{Cu}(531)^{17}$ or from an incomplete multilayer desorption at $340 \mathrm{~K}$. Moreover, a shift to lower temperature is observed at increasing molecular doses. The intensity of the desorption features observed in $\mathrm{H}_{2}^{+}$, $\mathrm{H}_{2} \mathrm{O}^{+}, \mathrm{CO}^{+}$, and $\mathrm{CO}_{2}^{+}$spectra increases for increasing RR-TA doses, thus ruling out the attribution of their origin only to desorption of vacuum residuals. Moreover, in the corresponding $\mathrm{m} / \mathrm{e}=58$ and 76 spectra, no desorption features are observed between 430 and $480 \mathrm{~K}$ for the lowest molecular coverages, confirming that the desorption peak comes from molecular desorption for the highest coverages.

Overall in the multilayer regime, large fragments of RR-TA molecules are detected suggesting desorption of intact molecular RR-TA, while RR-TA decomposes into smaller fragments when desorbed from a monolayer coverage. This observation is indicative of a strong interaction between the molecule and the oxide surface, stronger than 
the intramolecular bonds. A rough estimate of the desorption temperature can be given by the Readhead formula. To break a $\mathrm{C}-\mathrm{C}$ bond $(90 \mathrm{kcal} / \mathrm{mol})$, the expected temperature is enormous $\sim 1300 \mathrm{~K}$. The process of decomposition is probably a two-step process with an adsorbed intermediate. As previously reported, decomposition of RR-TA from the chemisorbed layer has been evidenced on other surfaces, such as $\mathrm{Cu}(110), \mathrm{Cu}(531), \mathrm{Ni}(110)$, and $\mathrm{Pd}(111)$, with the main decomposition products being hydrogen, carbon dioxide, and water as observed herein and where different decomposition pathways have been proposed. ${ }^{7,11,16,17}$ In the case of $\mathrm{Cu}(110)$, the following decomposition reaction was suggested: ${ }^{22}$

$$
\begin{gathered}
\mathrm{OOC}-\mathrm{HCOH}-\mathrm{HCOH}-\mathrm{COOH} \rightarrow 2 \mathrm{CO}_{2} \\
+2 \mathrm{H}_{2} \mathrm{O}+2 \mathrm{C}+1 / 2 \mathrm{H}_{2} .
\end{gathered}
$$

However, the presence of CO from the TPD cannot be ascribed to $\mathrm{CO}_{2}$ decomposition in the mass spectrometer. Indeed the relative ion currents for $\mathrm{CO}_{2}$ are 100 and 13 for $\mathrm{m} / \mathrm{e}=44$ and 28, respectively, at an impact energy of $90 \mathrm{eV}$. The $\mathrm{m} / \mathrm{e}=28$ signal is stronger in our case and cannot come from $\mathrm{CO}_{2}$ ionization only. This might be explained by another decomposition pathway, supported by the presence of $\mathrm{C}(285 \mathrm{eV})$ at the end of TPD experiments, as described later by XPS experiments (Fig. 4).

In the multilayer regime, RR-TA molecules are expected to form $\mathrm{H}$ bonds. The activation energy and order of desorption in the multilayer regime can be estimated using the leading edge analysis. ${ }^{28,30,31}$ The method is based on the ansatz of desorption rate of Polanyi and Wigner, ${ }^{28,31}$

$$
r_{d}=\frac{-d \theta}{d t}=v(\theta) \theta^{n(\theta)} e^{\frac{-E_{a}(\theta)}{k_{B} T}}
$$

where $v$ is a the pre-exponential factor, $\theta$ is the adsorbate coverage, $n$ is the desorption order, and $E_{a}$ is the activation energy. At the desorption threshold, the adsorption coverage has not changed significantly yet so that $v, n$, and $E_{a}$ can be considered as constants. If the sample is linearly heated and with an efficient differential pumping, the ion current detected $i_{d}(T)$, proportional to the partial pressure, is considered to be proportional to $\frac{-d \theta}{d t}$. Equation (1) can be, thus, rearranged as

$$
i_{d}(T) \propto\left(\int_{T}^{\infty} i_{d}\left(T^{\prime}\right) d T^{\prime}\right)^{n} \times e^{\frac{-E_{a}}{k_{B} T}}
$$

Taking the logarithm of Eq. (2), defined as $I_{d}(n, T)$, the previous equation can be linearized as

$$
I_{d}(n, T)=\ln \left[i_{d}(T)\right]-n \ln \left[\int_{T}^{\infty} i_{d}\left(T^{\prime}\right) d T^{\prime}\right]=K-\frac{E_{a}}{k_{B} T} .
$$

Based on these considerations, $I_{d}(n, T)$ should have a linear dependence on $1 / T$ with a slope $E_{a} . I_{d}(n, T)$ vs $1 / T$ is then drawn for different values of $n$ [Fig. 3(a)] to establish the best value that linearizes the signal at the onset of desorption. This analysis is applied in this work for the highest doses (40 and $54 \AA$ ) and for the desorption peaks $\mathrm{m} / \mathrm{e}=58$ and 76 at $335 \mathrm{~K}$. An order $n=0$ (Fig. 3) is found to linearize at best the signal leading to an activation energy in the range $37-39 \mathrm{kcal} / \mathrm{mol}$. The zero order is typical for autocatalytic desorption as in the case of water ice and agrees with a peak shift to higher temperatures with increasing doses (Fig. 1). Assuming that layers of RR-TA are hydrogen bonded through carboxylic dimer rings, a value of $18.5-19.5 \mathrm{kcal} / \mathrm{mol}$ is
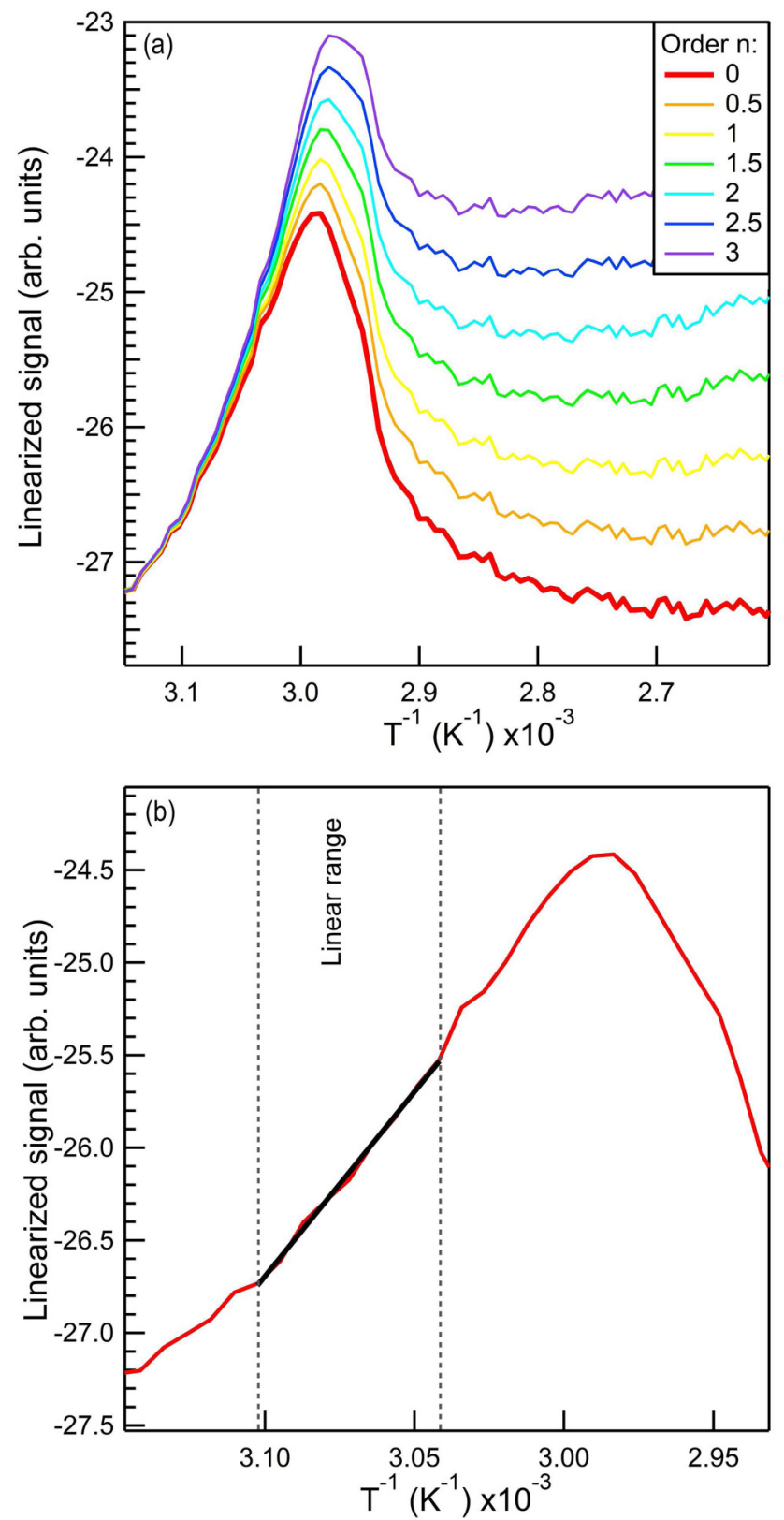

FIG. 3. (a) $I_{d}(n, T)$ linearized spectra plotted for different values of the desorption order $n$ for $\mathrm{m} / \mathrm{e}=58$ and $54 \AA$ of TA. (b) Zoom on $I_{d}(n=0, T)$. The linear fit of $I_{d}(n, T)$ at the edge of the desorption is represented by a black line. 


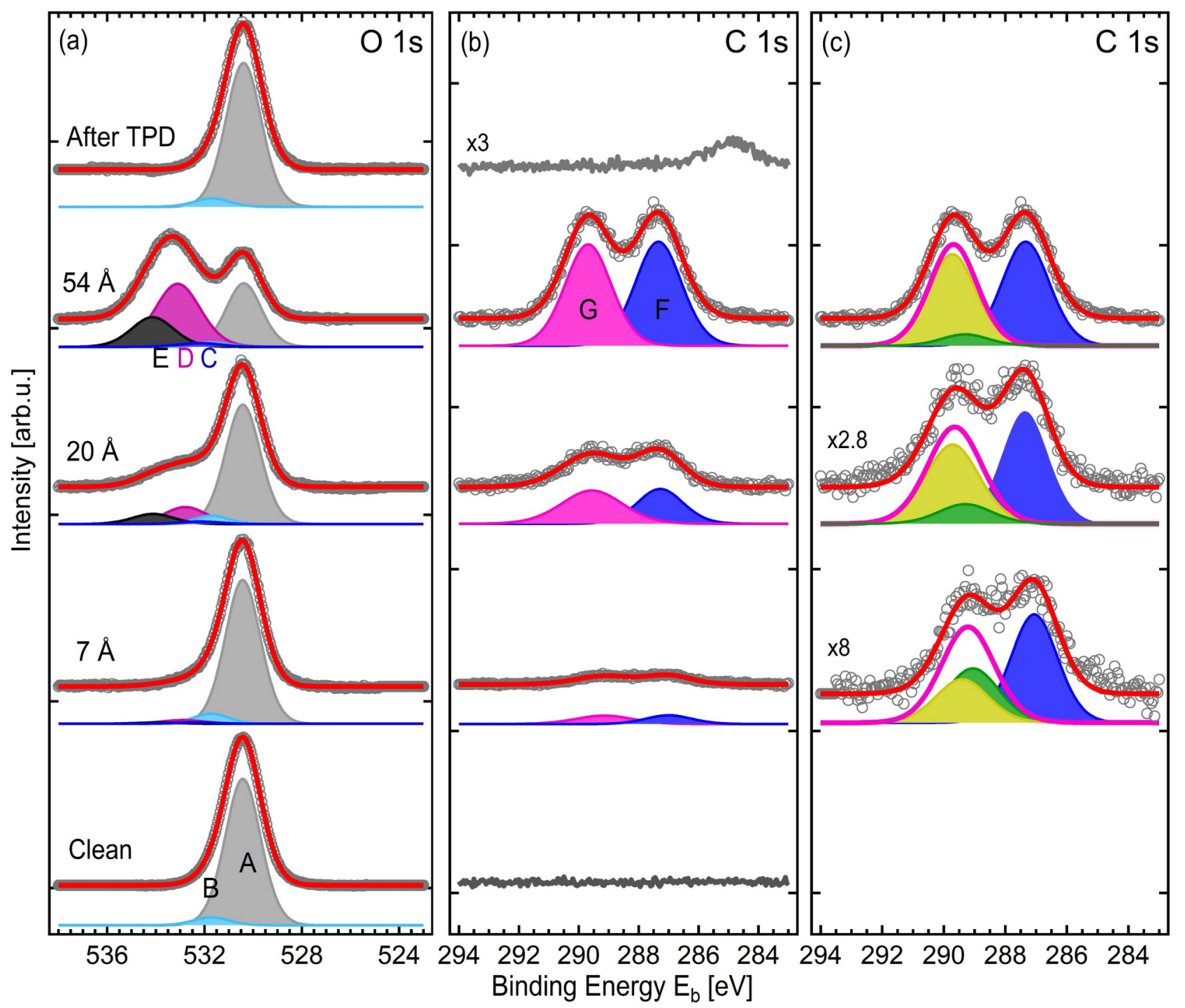

FIG. 4. Evolution of O1s (a) and C1s (b) peaks for RR-TA increasing doses on the rutile $\mathrm{TiO}_{2}(110)$ surface and after a TPD experiment; (c) same as (b) where the $\mathrm{COO}^{-}$and $\mathrm{COOH}$ contributions are represented by the green (dark grey) the yellow (light grey) peaks, respectively. Spectra are vertically shifted for sake of clarity and normalized to the peak height. Raw data and fitted component sums are represented by grey dots and a red (solid) line, respectively. The peak fitting attribution is detailed in the text.

found per hydrogen bond, an order of magnitude in agreement with previous findings $(14-15 \mathrm{kcal} / \mathrm{mol}){ }^{32}$

\section{B. Chemical nature of RR-TA adlayers on rutile $\mathrm{TiO}_{2}(\mathbf{1 1 0})$}

The chemical state of RR-TA molecules in the multilayer regime was investigated by XPS. The $\mathrm{O} 1 \mathrm{~s}$ and $\mathrm{C} 1 \mathrm{~s}$ spectra recorded for the clean $\mathrm{TiO}_{2}(110)$ surface and for increasing doses of RR-TA in the multilayer regime are presented in Fig. 4, and the corresponding fit parameters are summarized in Tables I and II. The fit performed is based on the previous considerations for RR-TA adsorption on rutile in the monolayer regime, where monotartrate molecules are observed. The O1s region of the clean rutile surface displays two contributions $\mathrm{A}$ and $\mathrm{B}$ at 530.4 and $531.7 \mathrm{eV}$, attributed to the $\mathrm{TiO}_{2} \mathrm{O}$ lattice atoms and the surface hydroxyl groups, respectively. Based on our previous work, ${ }^{24}$ following
RR-TA deposition, three molecular contributions are identified, $\mathrm{C}, \mathrm{D}$, and $\mathrm{E}$. Component $\mathrm{C}$ is related to the carboxylate functionality $\mathrm{COO}^{-}$, D to a superposition of the $\mathrm{C}=\mathrm{O}$ oxygen atoms and the $\mathrm{OH}$ alcohol groups $\left(\mathrm{C}-\underline{\mathrm{OH}}_{\mathrm{alc}}\right)$, while $\mathrm{E}$ to the acidic $\mathrm{OH}$ groups $\left(\mathrm{OH}_{\text {acid }}\right)$. To substantiate this decomposition, the fit of the spectra is first performed on the highest coverage spectrum $(54 \AA)$, where the molecular contributions prevail over the $\mathrm{TiO}_{2}$ substrate ones. The fullwidth at half-maximum (FWHM) and the peak binding energies determined are then kept fixed to fit the lower RR-TA dose spectra, where the presence of RR-TA results only in O1s peak shouldering at high binding energies. Some constraints on the peak areas are also used; for a $7 \AA$ layer, close to the monolayer saturation, the analysis is consistent with a majority presence of monotartrate species. As the RR-TA dose increases, the intensities of peaks $\mathrm{D}$ and $\mathrm{E}$, predominantly associated with the presence of protonated $\mathrm{COOH}$ groups, largely increases, suggesting the presence of fully 
TABLE I. O1s peak parameters [binding energy $\left(\mathrm{E}_{\mathrm{b}}\right)$ and relative area (RA)] used for the fit presented in Fig. 4. For components A and B, the FWHM is $1.7 \mathrm{eV}$, while for peaks C, D, and E, the FWHM is $2.0 \mathrm{eV}$. Error bars on $\mathrm{E}_{\mathrm{b}}$ are of the order of $0.1 \mathrm{eV}$.

\begin{tabular}{|c|c|c|c|c|c|c|c|c|c|c|}
\hline \multirow[b]{2}{*}{ Coverage } & \multicolumn{2}{|c|}{$\mathrm{A}-\mathrm{O}_{\text {lat }}$} & \multicolumn{2}{|c|}{$\mathrm{B}-\mathrm{O}_{\mathrm{b}} \mathrm{H}$} & \multicolumn{2}{|c|}{$\mathrm{C}-\mathrm{COO}^{-}$} & \multicolumn{2}{|c|}{$\mathrm{D}-\mathrm{C}=\underline{\mathrm{O}}, \mathrm{C}-\underline{\mathrm{OH}}_{\mathrm{alc}}$} & \multicolumn{2}{|c|}{$\mathrm{E}-\mathrm{COOH}$} \\
\hline & $\begin{array}{c}E_{b} \\
(e V)\end{array}$ & $\begin{array}{l}\text { RA } \\
(\%)\end{array}$ & $\begin{array}{c}\mathrm{E}_{\mathrm{b}} \\
(\mathrm{eV})\end{array}$ & $\begin{array}{l}\text { RA } \\
(\%)\end{array}$ & $\begin{array}{c}\mathrm{E}_{\mathrm{b}} \\
(\mathrm{eV})\end{array}$ & $\begin{array}{l}\text { RA } \\
(\%)\end{array}$ & $\begin{array}{c}\mathrm{E}_{\mathrm{b}} \\
(\mathrm{eV})\end{array}$ & $\begin{array}{l}\text { RA } \\
(\%)\end{array}$ & $\begin{array}{c}\mathrm{E}_{\mathrm{b}} \\
(\mathrm{eV})\end{array}$ & $\begin{array}{l}\text { RA } \\
(\%)\end{array}$ \\
\hline Clean & 530.4 & $94.9 \pm 0.2$ & 531.7 & $5.1 \pm 0.2$ & & & & & & \\
\hline $7 \AA$ & 530.4 & $89.0 \pm 0.6$ & 531.7 & $6.3 \pm 0.1$ & 532.3 & $1.1 \pm 0.1$ & 532.9 & $2.7 \pm 0.4$ & 533.9 & $0.9 \pm 0.2$ \\
\hline $20 \AA$ & 530.4 & $73.1 \pm 3.5$ & 531.7 & $5.1 \pm 0.3$ & 532.2 & $1.8 \pm 0.3$ & 532.9 & $12.5 \pm 1.9$ & 534.1 & $7.5 \pm 2.5$ \\
\hline $54 \AA$ & 530.4 & $33.6 \pm 1.8$ & 531.7 & $2.4 \pm 1.9$ & 532.3 & $3.4 \pm 2.4$ & 533.1 & $40.6 \pm 3.4$ & 533.9 & $20.0 \pm 2.9$ \\
\hline After TPD & 530.4 & $94.4 \pm 2.1$ & 531.7 & $5.6 \pm 2.1$ & & & & & & \\
\hline
\end{tabular}

protonated RR-TA molecules in the stacking of multilayers. Finally, following TPD, the O1s spectrum recovers its initial line shape.

For the $\mathrm{C} 1 \mathrm{~s}$ region, two contributions were identified at $\sim 287$ and $\sim 289 \mathrm{eV}^{24}$ The low binding energy peak (herein named $\mathrm{F}$ ) was attributed to the central $\mathrm{C}-\mathrm{OH}$ carbon atoms $[C(2), C(3)]$, while the one at higher $\mathrm{E}_{\mathrm{b}}$ (herein named $\mathrm{G}$ ) to a superposition of $\mathrm{COO}^{-}$and $\mathrm{COOH}$ groups. As a matter of fact, unlike what is observed for RR-TA molecules and other carboxylic acids adsorbed on $\mathrm{Cu}(110),{ }^{24,33-36}$ components of carboxylate and carboxylic $\mathrm{C}$ atoms are not resolved on $\mathrm{TiO}_{2}(110)$, as previously observed for terephthalic acid adsorption on the same rutile surface. ${ }^{37}$ Despite the superposition of $\mathrm{COO}^{-}$and $\mathrm{COOH}$ contributions on $\mathrm{TiO}_{2}(110)$, information on the evolution of RR-TA chemical form may still be gained by considering the energy splitting between peaks $F$ and $G$ and the relative variation of their FWHM. Some constraints are used for the fit, namely, the intensity ratio $\mathrm{F} / \mathrm{G}=1$, according to the molecular stoichiometry, and the FWHM of peak F, since no variation is expected for this peak which is related to the central $\mathrm{C}-\mathrm{OH}$ carbon atoms. The fit is first performed for the highest coverage (54 $\AA$ ), where the two peaks $F$ and $G$ are clearly discerned, to estimate the width of peak $F$ and to use it for the fit of the lower coverage spectra. In the multilayer regime, upon increasing RR-TA doses, the energy splitting increases progressively from 2.1 to $2.4 \mathrm{eV}$. For the highest RR-TA dose, peak $\mathrm{G}$ is

TABLE II. C1s peak parameters [binding energy (Eb), FWHM, and relative area (RA)] used for the spectra presented in Fig. 4. The binding energy difference between peaks $\mathrm{B}$ and $\mathrm{A}, \Delta(\mathrm{B}-\mathrm{A})(\mathrm{eV})$, is also reported. Error bars on $\mathrm{E}_{\mathrm{b}}$ are of the order of $0.1 \mathrm{eV}$.

\begin{tabular}{|c|c|c|c|c|c|c|c|}
\hline \multirow[b]{2}{*}{ Coverage } & \multicolumn{3}{|c|}{$\mathrm{F}-\mathrm{C}(2), \mathrm{C}(3)$} & \multicolumn{3}{|c|}{$\mathrm{G}-\mathrm{COO}^{-}, \underline{\mathrm{COOH}}$} & \multirow{2}{*}{$\begin{array}{c}\Delta(\mathrm{G}-\mathrm{F}) \\
{\left[\mathrm{COO}^{-},\right.} \\
\mathrm{COOH} \\
-\mathrm{C}(2), \\
\mathrm{C}(3)]\end{array}$} \\
\hline & $\begin{array}{c}\mathrm{E}_{\mathrm{b}} \\
(\mathrm{eV})\end{array}$ & $\begin{array}{c}\text { FWHM } \\
(\mathrm{eV})\end{array}$ & $\begin{array}{l}\text { RA } \\
(\%)\end{array}$ & $\begin{array}{c}E_{b} \\
(e V)\end{array}$ & $\begin{array}{c}\text { FWHM } \\
(\mathrm{eV})\end{array}$ & $\begin{array}{l}\text { RA } \\
(\%)\end{array}$ & \\
\hline Clean & 0 & & & 0 & & & 0 \\
\hline $7 \AA$ & 287.1 & 1.8 & $50 \pm 9$ & 289.2 & 2.1 & $50 \pm 9$ & 2.1 \\
\hline $20 \AA$ & 287.4 & 1.8 & $50 \pm 7$ & 289.6 & 2.1 & $50 \pm 7$ & 2.2 \\
\hline $54 \AA$ & 287.3 & 1.8 & $50 \pm 7$ & 289.7 & 1.8 & $50 \pm 7$ & 2.4 \\
\hline
\end{tabular}

found at $289.7 \mathrm{eV}$, in agreement with what was found for the carboxylic contribution of monotartrate RR-TA molecules on $\mathrm{Cu}(110){ }^{24}$ At the same time, the width of the high binding energy peak reduces by $0.2 \mathrm{eV}$. These considerations overall suggest the prevalence of one species $\left(\mathrm{COO}^{-} / \mathrm{COOH}\right)$ over the other, and more precisely, the dominant contribution of carboxylic acid groups, as expected in the formation of multilayers of fully protonated RR-TA molecules. This conclusion matches what is observed for other carboxylcontaining molecules on the same rutile surface ${ }^{37}$ and on other metallic surfaces. ${ }^{38,39}$ Moreover, for RR-TA adsorption on $\mathrm{Cu}(110)$, energy splitting values of 2.4 (Ref. 33) and $2.8 \mathrm{eV}$ (Ref. 24) have been reported between the central $\mathrm{C}-\mathrm{OH}$ and the $\mathrm{COOH}$ peaks. Splittings of 3.1 and $2.6 \mathrm{eV}$ have also been measured on $\mathrm{Cu}(111)^{18}$ and $\mathrm{Au}(111){ }^{24}$ The first value of $2.4 \mathrm{eV}$ is in agreement with the present work for the highest RR-TA dose, again confirming the dominant contribution of $\mathrm{COOH}$ species in the multilayer regime. An energy splitting of $2.6 \mathrm{eV}$ was also reported between the central $\mathrm{COH}$ and the $\mathrm{COOH}$ contribution for multilayer deposition of $\mathrm{R}$ malic acid on $\mathrm{Cu}(110) .{ }^{36}$ To evidence the increasing contribution of the carboxylic component over the carboxylate one, two components are discerned in peak $\mathrm{G}$, light and dark green (grey) peaks in Fig. 4(c). In the decomposition proposed the area ratio between $\mathrm{COO}^{-}$and $\mathrm{COOH}$ peaks is fixed to the one obtained from the O1s analysis. It is clear how at coverages near the first layer saturation, the $\mathrm{COO}^{-}$and $\mathrm{COOH}$ components are almost equivalent, while at increasing doses, the $\mathrm{COOH}$ prevails, as expected in nondeprotonated RR-TA multilayers. At last, a graphitic like $\mathrm{C} 1 \mathrm{~s}$ component at $-285 \mathrm{eV}$ remains at the surface after the thermal decomposition of the molecule.

\section{SUMMARY AND CONCLUSIONS}

The desorption and decomposition behavior of RR-TA molecules on $\mathrm{TiO}_{2}(110)$ was investigated by TPD. While molecules desorb more or less intact from the multilayer, they decompose in the monolayer regime, which indicates a strong interaction with the substrate. Information on the evolution of the RR-TA chemical state in the multilayer regime is gained by XPS and overall from the analysis of the O1s and $\mathrm{C} 1 \mathrm{~s}$ core levels; a majority presence of intact biacid molecules is observed in the multilayer regime. 


\section{ACKNOWLEDGMENTS}

This work was supported by the French State Fund managed by the ANR within the Investissements d'Avenir program under Reference No. ANR-11-IDEX-0004-02, and more specifically within the framework of the Cluster of Excellence MATISSE.

${ }^{1}$ C. J. Baddeley and N. V. Richardson, "Scanning tunneling microscopy in surface science," in Nanoscience and Catalysis, edited by M. Bowker and P. R. Davies (Wiley-VCH, Weinheim, 2010), Vol. 1, pp. 1-27.

${ }^{2}$ A. J. Gellman, W. T. Tysoe, and F. Zaera, Catal. Lett. 145, 220 (2015).

${ }^{3}$ D. Y. Murzin, P. Mäki-Arvela, E. Toukoniitty, and T. Salmi, Catal. Rev. 47, 175 (2005).

${ }^{4}$ T. Mallat, E. Orglmeister, and A. Baiker, Chem. Rev. 107, 4863 (2007).

${ }^{5}$ S. M. Barlow and R. Raval, Surf. Sci. Rep. 50, 201 (2003).

${ }^{6}$ R. Raval, J. Phys. Condens. Matter 14, 4119 (2002).

${ }^{7}$ K.-H. Ernst, Phys. Status Solidi B 249, 2057 (2012).

${ }^{8}$ M. Ortega Lorenzo, S. Haq, T. Bertrams, P. Murray, R. Raval, and C. J. Baddeley, J. Phys. Chem. B 103, 10661 (1999).

${ }^{9}$ M. Ortega Lorenzo, C. J. Baddeley, C. Muryn, and R. Raval, Nature 404, 376 (2000).

${ }^{10}$ M. Ortega Lorenzo, V. Humblot, P. Murray, C. J. Baddeley, S. Haq, and R. Raval, J. Catal. 205, 123 (2002).

${ }^{11}$ T. E. Jones and C. J. Baddeley, Surf. Sci. 513, 453 (2002).

${ }^{12}$ T. E. Jones and C. J. Baddeley, J. Mol. Catal. A Chem. 216, 223 (2004).

${ }^{13}$ V. Humblot, S. Haq, C. Muryn, W. A. Hofer, and R. Raval, J. Am. Chem. Soc. 124, 503 (2002).

${ }^{14}$ W. A. Hofer, V. Humblot, and R. Raval, Surf. Sci. 554, 141 (2004).

${ }^{15}$ V. Humblot, S. Haq, C. Muryn, and R. Raval, J. Catal. 228, 130 (2004).

${ }^{16}$ M. Mahapatra and W. T. Tysoe, Surf. Sci. 629, 132 (2014).

${ }^{17}$ S. Baldanza, J. Ardini, A. Giglia, and G. Held, Surf. Sci. 643, 108 (2016).

${ }^{18}$ A. Rieger, C. Sax, T. Bauert, C. Wäckerlin, and K.-H Ernst, Chirality 30, 369 (2018).
${ }^{19}$ A. J. Gellman, Y. Huang, X. Feng, V. V. Pushkarev, B. Holsclaw, and B. S. Mhatre, J. Am. Chem. Soc. 135, 19208 (2013).

${ }^{20}$ V. Humblot, M. Ortega Lorenzo, C. J. Baddeley, S. Haq, and R. Raval, J. Am. Chem. Soc. 126, 6460 (2004).

${ }^{21}$ B. S. Mhatre, V. Pushkarev, B. Holsclaw, T. J. Lawton, E. C. H. Sykes, and A. J. Gellman, J. Phys. Chem. C 117, 7577 (2013).

${ }^{22}$ B. Behzadi, S. Romer, R. Fasel, and K.-H. Ernst, J. Am. Chem. Soc. 126, 9176 (2004).

${ }^{23}$ C. L. Pang, R. Lindsay, and G. Thornton, Chem. Rev. 113, 3887 (2013).

${ }^{24}$ E. Meriggio, R. Lazzari, S. Chenot, P. David, C. Méthivier, X. Carrier, G. Cabailh, and V. Humblot, Appl. Surf. Sci. 493, 1134 (2019).

${ }^{25} \mathrm{C}$. Méthivier, V. Humblot, and C.-M. Pradier, J. Phys. Chem. C 120, 27364 (2016).

${ }^{26}$ U. Diebold, Surf. Sci. Rep. 48, 53 (2003).

${ }^{27}$ H. Onishi, T. Aruga, and Y. Iwasawa, J. Catal. 146, 557 (1994).

${ }^{28}$ H.-L. Thi Le, R. Lazzari, J. Goniakowski, R. Cavallotti, S. Chenot, C. Noguera, J. Jupille, A. Koltsov, and J.-M. Mataigne, J. Phys. Chem. C 121, 11464 (2017).

${ }^{29}$ See: https://webbook.nist.gov/cgi/cbook.cgi?ID=C87694\&Mask=200\# Mass-Spec.

${ }^{30}$ P. A. Redhead, Vacuum 12, 203 (1962).

${ }^{31}$ D. A. King, Surf. Sci. 47, 384 (1975).

${ }^{32}$ S. Scheiner, Hydrogen Bonding: A Theoretical Perspective (Oxford University, New York, 1997).

${ }^{33}$ M. Parschau, B. Behzadi, S. Romer, and K.-H. Ernst, Surf. Interface Anal. 38, 1607 (2006).

${ }^{34}$ C. Roth and K.-H. Ernst, Top. Catal. 54, 1378 (2011).

${ }^{35}$ C. Roth, M. Parschau, and K.-H. Ernst, Chem. Phys. Chem. 12, 1572 (2011).

${ }^{36}$ C. Roth, D. Passerone, L. Merz, M. Parschau, and K.-H. Ernst, J. Phys. Chem. C 115, 1240 (2011).

${ }^{37}$ W. Zhang, L. Cao, L. Wan, L. Liu, and F. Xu, J. Phys. Chem. C 117, 21351 (2013).

${ }^{38}$ M. Wühn, J. Weckesser, and C. Wöll, Langmuir 17, 7605 (2001).

${ }^{39}$ W. Zhang, A. Nefedov, M. Naboka, L. Cao, and C. Wöll, Phys. Chem. Chem. Phys. 14, 10125 (2012). 